\title{
Selection Strategy for Sorghum Targeting Phosphorus-limited Environments in West Africa: Analysis of Multi-environment Experiments
}

\author{
Willmar L. Leiser, H. Frederick W. Rattunde,^ Hans-Peter Piepho, Eva Weltzien, Abdoulaye Diallo, \\ Albrecht E. Melchinger, Heiko K. Parzies, and Bettina I. G. Haussmann
}

\begin{abstract}
Although sorghum [Sorghum bicolor (L.) Moench] in West Africa (WA) is generally cultivated with limited or no fertilization on soils of low phosphorus availability, no assessments of the genetic variation among WA sorghum varieties for adaptation to low soil $P$ are known. We assessed grain yields of 70 diverse sorghum genotypes under $-P$ (no $P$ fertilization) and $+\mathrm{P}$ conditions at two locations in Mali over 5 yr. Genetic variation for grain yield under $-P$ conditions and the feasibility and necessity of sorghum varietal testing for grain yield under $-\mathrm{P}$ conditions were evaluated. Delayed heading dates $(0-9.8$ d) and reductions of grain yield (2-59\%) and plant height (13-107 $\mathrm{cm}$ ) were observed in $-P$ relative to the $+P$ trials. High estimates of genetic variance and broad-sense heritabilities were found for grain yield across both $-P\left(h^{2}=0.93\right)$ and $+P\left(h^{2}=\right.$ 0.92) environments. The genetic correlation for grain yield performance between $-P$ and $+\mathrm{P}$ conditions was high $\left(r_{\mathrm{G}}=0.89\right)$, suggesting that WA sorghum varieties generally possess good adaptation to low-P conditions. However, genotype $\times$ phosphorus crossover interaction was observed between some of the highest yielding genotypes from the $-\mathrm{P}$ and $+\mathrm{P}$ selected sets, with the variety IS 15401 showing specific adaptation to $-\mathrm{P}$. Direct selection for grain yield in $-\mathrm{P}$ conditions was predicted to be $12 \%$ more efficient than indirect selection in $+\mathrm{P}$ conditions. Thus, selection under $-\mathrm{P}$ conditions should be useful for sorghum improvement in WA.
\end{abstract}

W.L. Leiser, International Crops Research Institute for the SemiArid Tropics, BP 320 Bamako, Mali, and Institute of Plant Breeding, Seed Science and Population Genetics, Univ. of Hohenheim, 70593 Stuttgart, Germany; H.F.W. Rattunde and E. Weltzien, International Crops Research Institute for the Semi-Arid Tropics, BP 320 Bamako, Mali; H.-P. Piepho, Bioinformatics Unit, Institute of Crop Science, Univ. of Hohenheim, 70593 Stuttgart, Germany; A. Diallo, L'Institut d'Economie Rurale, Bamako, Mali; A.E. Melchinger, H.K. Parzies, and B.I.G. Haussmann, Institute of Plant Breeding, Seed Science and Population Genetics, Univ. of Hohenheim, 70593 Stuttgart, Germany. Received 29 Feb. 2012. `Corresponding author (f.rattunde@cgiar.org).

Abbreviations: aVD, average variance of differences; BLUP, best linear unbiased prediction; $\mathrm{G} \times \mathrm{E} \times \mathrm{P}$, genotype $\times$ environment $\times$ phosphoruslevel interaction; $\mathrm{G} \times \mathrm{P}$, genotype $\times$ phosphorus-level interaction; GCV, genetic coefficient of variation; GEI, genotype $\times$ environment interaction; RYR, relative yield reduction; WA, West Africa.

Corghum [Sorghum bicolor (L.) Moench] is a staple crop of the Savannah Zone of West and Central Africa. The adaptation of sorghum to the climatic and edaphic conditions of this zone is critical for food security, and increasingly for farm income. Most of Sub-Saharan African soils (75\%) show plant nutrient deficiency (IFDC, 2006). Limited soil phosphorus (P) availability is a serious and frequent constraint to sorghum and pearl millet [Pennisetum glaucum (L.) R. Br.] growth and productivity across the range of rainfall zones in West Africa (WA) (Buerkert et al., 2001). Although sorghum has a yield potential of several tons per hectare in WA, actual yields average only about $1 \mathrm{t} \mathrm{ha}^{-1}$ since 1960 (FAO, 2010), due in part to low soil fertility and low-input production systems (Vom Brocke et al., 2010). Deficiency in $\mathrm{P}$ is known to reduce growth and delay maturity (Fageria et al., 1988; Wissuwa and Ae,

Published in Crop Sci. 52:2517-2527 (2012)

doi: 10.2135/cropsci2012.02.0139

(C) Crop Science Society of America | 5585 Guilford Rd., Madison, WI 53711 USA

All rights reserved. No part of this periodical may be reproduced or transmitted in any form or by any means, electronic or mechanical, including photocopying, recording, or any information storage and retrieval system, without permission in writing from the publisher. Permission for printing and for reprinting the material contained herein has been obtained by the publisher. 
2001; Chen et al., 2008; Cichy et al., 2008). Doumbia et al. (1998) reported strong correlations between poor sorghum growth and $\mathrm{P}$ deficiency and aluminum toxicity in WA soils. In most of these soils, available P contents (Bray1) are below the critical level of $7 \mathrm{ppm} \mathrm{P}\left(=7 \mathrm{mg} \mathrm{P} \mathrm{kg}^{-1}\right.$ soil) (Manu et al., 1991; Doumbia et al., 2003). Although soils may have acceptable total $\mathrm{P}$ contents, the quantity of plant-available $\mathrm{P}$ is often very limited, because the majority of soil $\mathrm{P}(70-90 \%)$, and the little $\mathrm{P}$ applied as inorganic fertilizer, is being fixed in the soil as nonavailable $\mathrm{P}$ (e.g., Fe-, Al-phosphate) for plants (Holford, 1997).

The Guinea-race of sorghum originated in the WA savannah (De Wet and Harlan, 1972). The traditional landrace varieties of this race, along with newly bred varieties developed by introgressing exotic germplasm into local Guinea-race materials, are the predominant types of sorghum cultivated in the Sudanian zone from Senegal to Burkina Faso. However, no systematic assessment of the genetic variation among these farmer landrace varieties and newly bred varieties for adaptation to low soil $\mathrm{P}$ in WA is available. Further, the lack of knowledge of the extent and nature of genotype $\times$ phosphorus interactions and genotype $\times$ environment interactions across low-P environments impedes the design of WA sorghum breeding programs to effectively target adaptation to the low-P conditions that are very common for the region's resource-poor farmers.

This study evaluated the grain yields of diverse WA sorghum varieties grown under a sampling of low- and high-P environments. Our goal was to assess the necessity and feasibility of breeding sorghum specifically for low-P conditions in the Sudanian-zone of WA. Our objectives were to (i) describe the genetic variation for grain yield under $-\mathrm{P}$ and $+\mathrm{P}$ conditions of a diverse sample of cultivated sorghum varieties, (ii) assess the genotypic specificity of $-\mathrm{P}$ adaptation, and (iii) compare the relative efficiency of direct selection for grain yield under $-\mathrm{P}$ conditions vs. indirect selection, when testing under $+\mathrm{P}$ conditions.

\section{MATERIALS AND METHODS}

The 70 sorghum varieties used in this study are representative for the diversity of cultivars and breeding lines adapted to the Sudanian zone of Mali (Table 1). Approximately half of the entries were landrace varieties, all of which are classified as Guinea-race, the predominant race in Mali. These accessions are tall (height $>3 \mathrm{~m}$ ) with photoperiod sensitivity and grain size covering the range exhibited by this race in the Sudanian zone of Mali. Four of the latest maturing entries were susceptible to sorghum midge (Stenodiplosis sorghicola) and frequently suffered nearly complete grain losses, and were thus excluded from the analyses. The remaining entries were bred from biparental Guinea $\times$ Caudatum-race crossing and backcrossing (27 entries) or from a Guinea-race random-mating population (five entries). These bred varieties represent a continuum from Guinea- to Caudatum-race phenotypes for grain and glume characteristics, with diversity for plant height, and intermediate to nonsensitive photoperiod sensitivities. There is almost no genetic relationship between the landrace varieties and the bred varieties, as none of these landrace varieties occur in the pedigrees of varieties derived from biparental crossing, and only one landrace variety was among the 13 landraces parents of the Guinea Population (Rattunde et al., 1997) from which the five population derivatives originated.

Yield trials were conducted in Mali, WA, at the Kolombada $\left(12^{\circ} 40^{\prime} \mathrm{N}, 7^{\circ} 0^{\prime} \mathrm{W}\right)$ research station of the Institut d'Economie Rurale and the Samanko $\left(12^{\circ} 31^{\prime} \mathrm{N}, 8^{\circ} 4^{\prime} \mathrm{W}\right)$ station of the ICRISAT (Supplemental Fig. 1) from 2006 to 2010. All trials were rainfed, with rains differing in amount and frequency (Table 2). Two separate trials were conducted at each location and year: one with $(+\mathrm{P})$ and one without $(-\mathrm{P})$ phosphorus fertilization. The $+\mathrm{P}$ and $-\mathrm{P}$ trials were conducted in adjacent fields at Samanko, or in a single field divided into $+\mathrm{P}$ and $-\mathrm{P}$ sections at Kolombada. The $+\mathrm{P}$ fields were fertilized with diammonium phosphate $(18-46-0)$ at rates of 100 to $200 \mathrm{~kg} \mathrm{ha}^{-1}$ as basal fertilizer and urea $\left(50 \mathrm{~kg} \mathrm{ha}^{-1}\right)(46-0-0)$ as topdressing. The $-\mathrm{P}$ fields received only topdressing with urea at rates that gave approximately equivalent units of nitrogen as received by the + P fields at Samanko 2006 to 2010 and Kolombada 2009. The $-\mathrm{P}$ fields at Kolombada in 2006 to 2008 received only the same quantity of urea used as topdressing in the $+\mathrm{P}$ experiments. Each trial consisted of 70 genotypes sown in an $\alpha$-design with four complete replicates, each with 14 incomplete blocks of five plots. Field layouts differed among trials, with column numbers ranging from 15 to 35 and row numbers ranging from 8 to 20. Plots consisted of two 3-m rows with $75-\mathrm{cm}$ distance between rows and $30 \mathrm{~cm}$ between hills within rows. Hills were thinned to two plants, resulting in a total of approximately 9.8 plants $\mathrm{m}^{-2}$. A single border row separated each test plot to minimize neighbor effects. The guard rows were left unsown in 2006 to 2008, whereas they were sown with a common locally adapted variety in 2009 and 2010. In most years soil samples were analyzed after fertilizer application for plantavailable P, using the Bray-1 method (Bray and Kurtz, 1945), organic carbon, $\mathrm{pH}$ in $\mathrm{H}_{2} \mathrm{O}$ and aluminum-saturation (Table 2). The environmental mean plant-available soil P-levels (Bray-1 P) were above $14 \mathrm{ppm}\left(14 \mathrm{mg} \mathrm{P} \mathrm{kg}^{-1}\right.$ soil) in the $+\mathrm{P}$ and mostly below $10 \mathrm{ppm}$ (10 $\mathrm{mg} \mathrm{P} \mathrm{kg}^{-1}$ soil) in the $-\mathrm{P}$ trials.

\section{DATA ANALYSIS}

\section{Analysis of Individual Trials}

Each single environment trial was analyzed for grain yield with several spatial models as described in a companion study (Leiser et al., 2012); the optimum model was identified for each trial, and predicted values and standard errors were computed for each genotype, taking the factor genotype as fixed. The repeatability $\left(w^{2}\right)$ of each trial was calculated with a formula adjusted for unbalanced data sets (Eq. [19] in Piepho and Möhring, 2007):

$$
w^{2}=\frac{\sigma_{g}^{2}}{\sigma_{g}^{2}+\frac{\mathrm{VD}}{2}}
$$

where $\sigma_{g}^{2}$ is the genotypic variance component and VD is the average variance of differences between genotype means.

The genetic coefficient of variation (GCV) of each trial was calculated as: 


$$
\mathrm{GCV}=\frac{\sqrt{\sigma_{g}^{2}}}{\mu}
$$

where $\sigma_{g}^{2}$ is the genotypic variance component and $\mu$ the trial grand mean, to enable comparisons of genetic variance across trials of differing mean yields. As a measure for the extent of error in each trial, the average variance of differences (aVD) between genotypes was estimated and standardized by dividing the square root of aVD (= SEd) with the trial grand mean, to enable comparisons of error extent across trials of differing mean yields. Differences between means for $w^{2}$, GCV, and aVD between means across the $-\mathrm{P}$ and $+\mathrm{P}$ trials were tested with a two-sided $t$ test. The relative yield reduction (RYR) was calculated as: $\mathrm{RYR}=$ $100 \times\left[1-\left(\right.\right.$ MeanYield $_{-\mathrm{p}} /$ MeanYield $\left.\left._{+\mathrm{p}} \times 100\right)\right]$. Genetic correlations between yield performance in the $+\mathrm{P}$ and $-\mathrm{P}$ trials in each environment (location-year-combination) were calculated according to Cooper and DeLacy (1994), assuming no environmental covariance because of the experimental setup.

\section{Combined Analysis across Environments}

Eight of the nine $-\mathrm{P}$ trials and seven of the eight $+\mathrm{P}$ trials were used in a combined weighted mixed-model Restricted Maximum Likelihood (REML) analysis. Two trials, namely Kolombada 2008 $-\mathrm{P}$ and Samanko $2008+\mathrm{P}$, were excluded from the analysis, due to a low RYR, height reduction, and heading delay (Table 3), which could be explained by certain environmental constraints. A twostage multi-environment combined analysis was conducted so that adjusted means of each entry per trial could be used, where the adjusted means were computed separately for each trial accounting for any specifics such as spatial adjustment if needed. The adjusted means were used as response variate and the reciprocal squared standard error (SE) from each entry as weights (Möhring and Piepho, 2009). The residual variance was fixed, thus the specified residual variance-covariance matrix with the corresponding weights was
Table 1. Number of sorghum genotypes of landrace and research bred origins, and their classification into photoperiod-sensitivity and plant height groups.

\section{Photoperiod sensitivity Plant height}

Origin No. Strong Intermediate Weak Tall Short

\begin{tabular}{lrrrrrr}
\hline Farmer landrace & 34 & 6 & 21 & 7 & 34 & 0 \\
Research bred & 32 & 0 & 15 & 16 & 14 & 18 \\
\hline
\end{tabular}

used as residual term and no extra residual variance component was needed (Piepho, 1999). Smith et al. (2001) proposed a weighting method based on the variance-covariance matrix of the adjusted means specifically for analyses (e.g., incomplete blocks, spatial adjustment) where higher covariances are expected in the variance-covariance matrix. We did not detect high covariances in the single-trial variance-covariance matrixes of the spatially adjusted means or of the adjusted means derived from a model with random incomplete block effects, so we used the simpler method of Piepho (1999). Furthermore we correlated the best linear unbiased predictions (BLUPs) of a one-stage and two-stage analysis across the $-\mathrm{P}$ and $+\mathrm{P}$ trials. For the one-stage analysis we modeled random incomplete blocks within each trial and variance heterogeneity between trials. The weighted two-stage analysis was conducted with adjusted means from the single trial incomplete block analyses and their corresponding inverse squared SEs as weights. There was a very strong relationship for the $-\mathrm{P}$ and $+\mathrm{P}$ trials $\left(r_{-\mathrm{P}}=0.9985\right.$, $\left.r_{+\mathrm{p}}=0.9994\right)$ between the one- and two-stage analysis, suggesting that our weighting method was sufficient. Because BLUP values predict more accurately genotypic differences (Piepho et al., 2008), the genotype effect was considered random for the estimation of each BLUP value. The BLUPs were tested for significant differences against the grand mean and between each other with linear contrasts as implemented in the VTCOMPARISON procedure in Genstat 14 (http://www.vsni.co.uk/software/genstat [accessed 11 July 2012]). Broad-sense heritability $\left(h^{2}\right)$ within and across P-levels

Table 2. Characterization of environments for sowing date, rains within the whole year (total rain), rains within the season after sowing (season rain), applied fertilizer, soil pH, soil plant-available $\mathrm{P}(\mathrm{Bray}-1 \mathrm{P})$, soil total $\mathrm{P}$, soil aluminum saturation ( $\mathrm{Al}^{3+}$-sat.), and soil organic carbon $\left(\mathrm{C}_{\text {org }}\right)$.

\begin{tabular}{|c|c|c|c|c|c|c|c|c|c|c|c|c|c|c|}
\hline \multirow[t]{2}{*}{ Location } & \multirow[t]{2}{*}{ Year } & \multirow[t]{2}{*}{ P-level } & \multirow[t]{2}{*}{ Sowing date } & \multicolumn{2}{|c|}{ Total rain } & \multicolumn{2}{|c|}{ Season rain } & \multicolumn{2}{|c|}{ Fertilizer } & \multirow{2}{*}{$\frac{\text { pH }}{\text { in } \mathrm{H}_{2} \mathrm{O}}$} & \multirow{2}{*}{$\frac{\text { Bray-1 P }}{\mathrm{mg} \mathrm{Pkg}^{-1}}$} & \multirow{2}{*}{$\frac{\text { Total P }}{\mathrm{mg} \mathrm{P} \mathrm{kg}^{-1}}$} & \multirow{2}{*}{$\frac{\mathrm{Al}^{3+} \text {-sat. }}{\text { in } \% \text { of CEC }}$} & \multirow{2}{*}{$\frac{\mathrm{C}_{\text {org }}}{\% \mathrm{CO}}$} \\
\hline & & & & $\mathrm{mm}$ & $d$ & $\mathrm{~mm}$ & $d$ & $\mathrm{~N} \mathrm{~kg} \mathrm{ha}^{-1}$ & $\mathrm{P} \mathrm{kg} \mathrm{ha}{ }^{-1}$ & & & & & \\
\hline \multirow[t]{2}{*}{ Kolombada } & 2006 & $+\mathrm{P}$ & 18 July 2006 & 906 & 53 & 611 & 32 & 41 & 20 & n.a. ${ }^{\dagger}$ & 16.60 & n.a. & n.a. & n.a. \\
\hline & & $-P$ & & & & & & 23 & & n.a. & 11.44 & n.a. & n.a. & n.a. \\
\hline \multirow[t]{2}{*}{ Kolombada } & 2007 & $+P$ & 5 July 2007 & 880 & 51 & 759 & 37 & 41 & 20 & 5.01 & 19.48 & n.a. & 14.35 & 0.26 \\
\hline & & $-P$ & & & & & & 23 & & 4.88 & 13.85 & n.a. & 21.02 & 0.25 \\
\hline \multirow[t]{2}{*}{ Kolombada } & 2008 & $+P$ & 10 July 2008 & 616 & 52 & 462 & 35 & 41 & 20 & n.a. & $16.5^{\ddagger}$ & n.a. & n.a. & n.a. \\
\hline & & $-P$ & & & & & & 23 & & n.a & n.a. & n.a & n.a & n.a \\
\hline \multirow[t]{2}{*}{ Kolombada } & 2009 & $+\mathrm{P}$ & 9 July 2009 & 720 & 59 & 587 & 49 & 29.5 & 20 & 5.14 & 16.02 & 108.73 & 1.58 & 0.28 \\
\hline & & $-P$ & & & & & & 23 & & 5.27 & 8.88 & 105.66 & 2.14 & 0.24 \\
\hline \multirow[t]{2}{*}{ Samanko } & 2006 & $+P$ & 27 June 2006 & 1008 & 63 & 765 & 57 & 29 & 17 & 5.01 & 14.44 & 106.24 & 8.82 & 0.33 \\
\hline & & $-P$ & 28 June 2006 & & & & & 46 & & 4.43 & 6.51 & 122.09 & 20.63 & 0.28 \\
\hline Samanko & 2007 & $-P$ & 16 July 2007 & 809 & 63 & 622 & 48 & 46 & & n.a. & 3.95 & n.a. & n.a. & n.a. \\
\hline \multirow[t]{2}{*}{ Samanko } & 2008 & $+P$ & 2 July 2008 & 1035 & 63 & 791 & 48 & 45.72 & 50.8 & n.a. & n.a. & n.a. & n.a. & n.a. \\
\hline & & $-P$ & 7 July 2008 & & & & & 46 & & n.a. & $8.00^{\ddagger}$ & n.a. & n.a. & n.a. \\
\hline \multirow[t]{2}{*}{ Samanko } & 2009 & $+P$ & 8 July 2009 & 1068 & 66 & 911 & 51 & 59 & 40 & 5.18 & 18.78 & 111.58 & 10.69 & 0.38 \\
\hline & & $-P$ & & & & & & 58.42 & & 4.83 & 7.40 & 111.70 & 22.82 & 0.29 \\
\hline \multirow[t]{2}{*}{ Samanko } & 2010 & $+P$ & 26 June 2010 & 1230 & 67 & 954 & 55 & 41 & 20 & 5.67 & 19.18 & n.a. & 8.00 & 0.37 \\
\hline & & $-P$ & & & & & & 40.9 & & 6.41 & 5.69 & n.a. & 2.00 & 0.19 \\
\hline
\end{tabular}

${ }^{\dagger}$ n.a. $=$ missing data

‡ Estimated value based on results from previous/next year. 
Table 3. Estimates of mean (GY, in $\mathrm{gm}^{-2}$ ), repeatability $\left(w^{2}\right)$, genetic coefficient of variation (GCV), standardized average variance of differences (aVD) for grain yield in nine trials without (-P) and eight trials with $P$ fertilization (+P), as well as the relative yield reduction (RYR), genetic correlation $\left(r_{G}\right)$ between grain yield performance under $-P$ vs. $+P$, height reduction $(\mathrm{HR}$, in $\mathrm{cm})$, and delay of heading (HD, in days) in $-\mathrm{P}$ relative to $+\mathrm{P}$ trials.

\begin{tabular}{|c|c|c|c|c|c|c|c|c|c|c|}
\hline Location & Year & P-level & GY & $w^{2}$ & GCV & aVD & $r_{G}$ & RYR & HR & HD \\
\hline & & & $\mathrm{gm}^{-2}$ & & $\%$ & $\%$ & & $\%$ & $\mathrm{~cm}$ & $d$ \\
\hline \multirow[t]{2}{*}{ Kolombada } & 2006 & $+P$ & 115.8 & 0.69 & 19.1 & 18.0 & 0.73 & 27 & -36.8 & 1.95 \\
\hline & & $-P$ & 84.6 & 0.69 & 19.3 & 18.4 & & & & \\
\hline \multirow[t]{2}{*}{ Kolombada } & 2007 & $+\mathrm{P}$ & 85.4 & 0.83 & 34.1 & 21.7 & 0.91 & 59 & -56.4 & 3.98 \\
\hline & & $-P$ & 35.2 & 0.74 & 21.9 & 18.2 & & & & \\
\hline \multirow[t]{2}{*}{ Kolombada } & 2008 & $+P$ & 157.3 & 0.77 & 15.3 & 11.7 & 0.99 & 07 & -13.4 & 0.01 \\
\hline & & $-P$ & 145.6 & 0.61 & 12.7 & 14.2 & & & & \\
\hline \multirow[t]{2}{*}{ Kolombada } & 2009 & $+\mathrm{P}$ & 177.4 & 0.87 & 24.9 & 13.6 & 0.83 & 43 & -67.4 & 7.95 \\
\hline & & $-P$ & 100.5 & 0.76 & 31.9 & 25.5 & & & & \\
\hline \multirow[t]{2}{*}{ Samanko } & 2006 & $+\mathrm{P}$ & 192.2 & 0.86 & 22.4 & 13.0 & 0.57 & 38 & -66.2 & 4.14 \\
\hline & & $-P$ & 118.8 & 0.87 & 31.2 & 16.9 & & & & \\
\hline Samanko & 2007 & $-P$ & 37.1 & 0.70 & 34.4 & 31.5 & & & & \\
\hline \multirow[t]{2}{*}{ Samanko } & 2008 & $+P$ & 113.8 & 0.84 & 27.0 & 16.7 & 0.50 & 02 & -30.3 & -1.78 \\
\hline & & $-P$ & 111.6 & 0.77 & 23.9 & 18.5 & & & & \\
\hline \multirow[t]{2}{*}{ Samanko } & 2009 & $+P$ & 299.7 & 0.84 & 23.4 & 14.4 & 0.78 & 57 & -98.8 & 9.82 \\
\hline & & $-P$ & 130.0 & 0.86 & 38.3 & 22.1 & & & & \\
\hline \multirow[t]{2}{*}{ Samanko } & 2010 & $+\mathrm{P}$ & 202.0 & 0.81 & 21.1 & 14.4 & 0.78 & 51 & -107.5 & 7.61 \\
\hline & & $-P$ & 98.1 & 0.77 & 28.8 & 22.0 & & & & \\
\hline Mean & & $+\mathrm{P}$ & 168.0 & 0.81 & 23.4 & 15.4 & & & & \\
\hline \multirow[t]{2}{*}{ Mean } & & $-P$ & 95.7 & 0.75 & 26.9 & 20.8 & & & & \\
\hline & & & * & $\mathrm{NS}^{\dagger}$ & NS & * & & & & \\
\hline
\end{tabular}

${ }^{*} p<0.05$ in two-sided $t$ test.

${ }^{\dagger} \mathrm{NS}=$ not significant in two-sided $t$ test.

was calculated with an adjusted formula for unbalanced trials with random genotype effects (Cullis et al., 2006):

$$
h^{2}=1-\frac{\overline{\mathrm{v}}_{\mathrm{BLUP}}}{2 \sigma_{g}^{2}}
$$

where $\overline{\mathrm{v}}_{\text {BLUP }}$ is the mean variance of a difference between two BLUPs and $\sigma_{g}^{2}$ is the genotypic variance component. The $h^{2}$ estimate was used for describing the heritability of the multienvironment data set, while $w^{2}$ was used as measure for repeatability of each individual trial.

Mixed models were fitted within each P-level to estimate genotype $\times$ environment interaction (GEI) and environmental factors contributing to GEI (Table 4). To detect the GEI pattern a three-way-interaction model was fitted with genotypes and years considered as random and locations as fixed. The existence of any major definable mega-environments needing to be considered for characterizing genotypic performance across $-\mathrm{P}$ or $+\mathrm{P}$ environments was examined by the extent to which GEI could be explained by various environmental parameters using a model that included genotype, trials, and environmental factors (Table 4), all considered as random effects.

The model within one P-level and environmental factors can be stated as:

$$
\mathrm{Y}_{i j k}=\mu+\mathrm{G}_{i}+\mathrm{E}_{j}+\mathrm{GE}_{i j}+\mathrm{GF}_{i k}+\mathrm{e}_{i j k},
$$

where $\mathrm{Y}_{i j k}$ is the adjusted mean of the ith genotype in the $j$ th environment within the $k$ th class of the environmental factor, $\mu$ is the grand mean, $\mathrm{G}_{i}$ is the effect of the $i$ th genotype, $\mathrm{E}_{j}$ the effect of the $j$ th environment, $\mathrm{F}_{k}$ the effect of the $k$ th environmental parameter for explaining GE, and $e_{i j k}$ is the error of each $\mathrm{Y}_{i j k}$ considered by the reciprocal squared SE as weights.
A combined analysis across P-levels was conducted with P-level as fixed and genotypes and environments (locationyear-combination) as random. The factorial model can be stated as:

$$
\mathrm{Y}_{i j k}=\mu+\mathrm{P}_{i}+\mathrm{EP}_{i j}+\mathrm{GP}_{i k}+\mathrm{GEP}_{i j k}+\mathrm{e}_{i j k} \text {, }
$$

where $\mathrm{Y}_{i j k}$ is the adjusted mean of the kth genotype $(\mathrm{G})$ in the $j$ th environment $(\mathrm{E})$ and the $i$ th $\mathrm{P}-\mathrm{level}(\mathrm{P})$. An unstructured variance-covariance model was fitted for P-level $(\mathrm{P})$ in each interaction. The reciprocal squared SE of each $\mathrm{Y}_{i j k}$ were considered as weights. A four-way-interaction model with P-level, year, location, and genotypes had convergence problems and thus will not be presented. Assuming covariances between trials the genetic correlation of grain yield between $+\mathrm{P}$ and $-\mathrm{P}$ across all environments was calculated as:

$$
r_{G}=\frac{\sigma_{G(-\mathrm{P}+\mathrm{P})}}{\left(\sigma_{G(-\mathrm{P})} \sigma_{G(+\mathrm{P})}\right)}
$$

where $\sigma_{G(-\mathrm{P}+\mathrm{P})}$ is the covariance of genotype means in $-\mathrm{P}$ and $+\mathrm{P}$ and $\sigma_{G(-\mathrm{P})}$ and $\sigma_{G(+\mathrm{P})}$ are the genotypic standard deviations within the $-\mathrm{P}$ and the $+\mathrm{P}$ fertility level, respectively.

For the 15\% best yielding genotypes (top 10) within each $\mathrm{P}-$ level a linear regression of grain yield against the trial mean soil Bray-1 P (mg P kg${ }^{-1}$ soil) was conducted with 13 trials having measured and two trials having estimated Bray-1 P values (Table 2).

Genotypic superiority for grain yield across $-\mathrm{P}$ and $+\mathrm{P}$ trials was calculated as the selection differential $\left(S=\mu_{\text {select }}-\mu_{\text {grand }}\right)$ of the 5,10 , and $15 \%$ top yielding genotypes in $-\mathrm{P}$ and $+\mathrm{P}$. The relative efficiency of response to indirect vs. direct selection for grain yield under $-\mathrm{P}$ conditions was estimated as: 


$$
R_{\mathrm{id}} / R_{\mathrm{d}}=r_{\mathrm{G}} \times h_{+\mathrm{P}} / h_{-\mathrm{P}},
$$

where $R_{\text {id }}$ and $R_{\mathrm{d}}$ are the indirect and direct response to selection, respectively, $r_{G}$ the genetic correlation coefficient between $+\mathrm{P}$ and $-\mathrm{P}$ and $h_{+\mathrm{P}}$ and $h_{-\mathrm{P}}$ the square root of the broad-sense heritability $\left(h^{2}\right)$ within the $+\mathrm{P}$ and $-\mathrm{P}$ environments, respectively (Atlin and Frey, 1989). All data analyses were conducted with the Genstat 14 software.

\section{RESULTS}

\section{Mean Performance Under High- and Low- Phosphorus Soil Conditions}

The $-\mathrm{P}$ trials generally exhibited reduced grain yields, plant heights, and delayed heading, relative to the corresponding $+\mathrm{P}$ trials (Table 3 ). The mean grain yield across the $-\mathrm{P}$ environments was significantly lower than across the $+\mathrm{P}$ environments, although there was a rather big range $(2-59 \%)$ for $\mathrm{RYR}$ in $-\mathrm{P}$ vs. $+\mathrm{P}$ conditions, with some pairs of trials (Kolombada 2008 and Samanko 2008) showing almost no yield difference between $-\mathrm{P}$ and $+\mathrm{P}$. High RYR in $-\mathrm{P}$ experiments was strongly associated with large delay of heading $\left(R^{2}=0.75^{\star \star}\right)$ and large height reduction $\left(R^{2}=0.67 \star \star\right)$.

Examination of RYR, plant heights, and delayed heading levels identified two environments that appeared to be inappropriate for assessing differential genotypic performance under contrasting $\mathrm{P}$ conditions. The Kolombada 2008 -P trial was in a field that had been fallow for many years and had relatively high mean yield $\left(1.45 \mathrm{t} \mathrm{ha}^{-1}\right)$, and no yield reduction or delay in flowering compared to the $+\mathrm{P}$ trial. The Samanko $2008+\mathrm{P}$ trial appeared to suffer from shallow soil depth, with very poor plant growth throughout the season in three of four replicates despite high and repeated fertilization and achieved a mean yield of only $1.1 \mathrm{t} \mathrm{ha}^{-1}$ (Table 2 and Table 3). Therefore these two trials were excluded from the combined analyses.

\section{Genetic Variation Under Low- and High- Phosphorus Conditions}

The mean repeatability $\left(w^{2}\right)$ estimates for grain yield in the $-\mathrm{P}$ trials were slightly but nonsignificantly lower than in the $+\mathrm{P}$ trials (Table 3 ). Although there was a significant higher error $(\mathrm{aVD})$ in the $-\mathrm{P}$ trials, the GCV tended to be higher in $-\mathrm{P}$ relative to $+\mathrm{P}$, which resulted in nearly the same level of repeatability in $-\mathrm{P}$ as in the $+\mathrm{P}$ conditions (Table 3). We observed medium to high genetic correlations $\left(0.5 \leq r_{\mathrm{G}} \leq 0.99\right)$ for grain yield between $-\mathrm{P}$ and $+\mathrm{P}$ in each environment. No relationship was observed $(r=$ -0.22 n.s.) between $r_{\mathrm{G}}$ for grain yield and RYR across the pairs of $-\mathrm{P}$ and $+\mathrm{P}$ trials over all environments, even if Samanko 2008 was excluded.
Table 4. Environmental factors and their factor classes.

\begin{tabular}{lccccc}
\hline $\begin{array}{c}\text { Factor } \\
\text { class }\end{array}$ & $\begin{array}{c}\text { Sowing } \\
\text { date }\end{array}$ & $\begin{array}{c}\text { Grain } \\
\text { yield }\end{array}$ & $\begin{array}{c}\text { Rain } \\
\text { amount }\end{array}$ & $\begin{array}{c}\text { Days with } \\
\text { rain }\end{array}$ & \begin{tabular}{c} 
Bray-1 P \\
\hline
\end{tabular} \\
\hline & 20-30 June & $0-50$ & $600-800$ & $50-55$ & $3-7$ \\
2 & 01-10 July & $50-100$ & $800-900$ & $55-60$ & $7-10$ \\
3 & 10-20 July & $100-150$ & $900-1000$ & $60-65$ & $10-13$ \\
4 & & $150-200$ & $1000-1100$ & $>65$ & $13-17$ \\
5 & & $>200$ & $>1100$ & & $17-20$ \\
\hline
\end{tabular}

Table 5. Variance components for grain yield ( \pm SE) within eight trials without $(-P)$ and seven trials with $P$ fertilization (+P) analyzed with a mixed-model Restricted Maximum Likelihood approach, as well as the standardized average variance of differences (aVD), genetic coefficient of variation (GCV), and broad-sense heritability $\left(h^{2}\right)$ estimates.

\begin{tabular}{|c|c|c|}
\hline Term & $-P$ & $+\mathrm{P}$ \\
\hline$\sigma_{G}^{2}$ & $387.3^{\star \star} \pm 85.0$ & $734.6^{\star \star} \pm 186.1$ \\
\hline$\sigma_{G \times Y}^{2}$ & $90.3^{*} \pm 35.2$ & $250.1^{\star \star} \pm 84.0$ \\
\hline$\sigma_{G \times L}^{2}$ & $51.5 \pm 27.0$ & $318.9^{\star \star} \pm 91.7$ \\
\hline$\sigma_{G \times Y \times L}^{2}$ & $139.0^{\star *} \pm 36.8$ & $173.5^{\star} \pm 81.9$ \\
\hline aVD & 8.50 & 5.84 \\
\hline GCV & 22.85 & 15.21 \\
\hline$h^{2}$ & 0.93 & 0.92 \\
\hline
\end{tabular}

* Significant at $p<0.05$.

** Significant at $p<0.01$.

\section{Variance Components Under Low- and High- Phosphorus Conditions}

Significant but rather small genotype $\times$ environment interaction (GEI) was detected across the $-\mathrm{P}$ trials (Table 5). The GEI variance components were smaller than the genotypic components, which contributed to the high heritability estimate $\left(h^{2}\right)$ over all $-\mathrm{P}$ trials. Most of the GEI in $-\mathrm{P}$ was of more complex nonexploitable threeway interaction $(G \times Y \times L)$. The GCV and aVD estimates across the $-\mathrm{P}$ trials were higher than for the $+\mathrm{P}$ trials (Table 5) and the heritability estimate was comparable to that of the $+\mathrm{P}$ trials, similar to the single trial repeatability estimates. Inclusion of environmental factors (Table 4) generally explained relatively small portions of GEI across -P environments (Table 6). The amount of total annual rainfall proved to be the most important factor explaining $43 \%$ of GEI in -P. However, the amount of rainfall or days with rain during the growing season (after sowing) explained less GEI than total seasonal rainfall (data not shown). The GEI was reduced by $18 \%$ by including a factor for the trial mean yield level and by only $9 \%$ by including factors for date of sowing (late-June to mid-July sowings) or soil plant-available $\mathrm{P}$, as estimated by Bray-1 P. Therefore all $-\mathrm{P}$ trials were considered as one population of environments for further analyses since a subdivision of our environmental sample for controllable environmental factors was of no explanatory value.

The GEI across $+\mathrm{P}$ trials was significant and appeared to be somewhat more important in $+\mathrm{P}$ than in $-\mathrm{P}$ trials, with the 
Table 6. Variance components for total genotype $\times$ environment interaction (GEI) and residual GEI after accounting for genotypic interactions with specific environmental factors, and the absolute difference between total and residual variance components, using mixed-model Restricted Maximum Likelihood analyses across environments with $\mathrm{P}$ fertilization (+P) and without fertilization (-P).

\begin{tabular}{|c|c|c|c|c|c|c|c|}
\hline & \multirow[b]{2}{*}{ P-level } & \multirow[b]{2}{*}{ Total } & \multicolumn{5}{|c|}{ Residual GEI after accounting for } \\
\hline & & & Sowing date & $\mathrm{GY}^{\dagger}$ & Rain amount & Days with rain & Bray-1 P \\
\hline$+\mathrm{P}$ & GEI & 596.9 & 500.4 & 608.1 & 503.2 & 291.1 & 587.6 \\
\hline$-P$ & GEI & 249.6 & 226.4 & 204.8 & $\begin{array}{l}142.6 \\
\Delta \mathrm{GEI}^{\ddagger}\end{array}$ & 234.3 & 226.3 \\
\hline$+P$ & $\triangle \mathrm{GEI}$ & & -96.4 & 11.2 & -93.6 & -305.8 & -9.3 \\
\hline$-P$ & $\triangle \mathrm{GEI}$ & & -23.2 & -44.8 & -106.9 & -15.3 & -23.3 \\
\hline
\end{tabular}

${ }^{\dagger} \mathrm{GY}=$ Trial grain yield class, Rain amount, and Days with rain over the entire year (see Tables 2 and 4);

${ }^{\ddagger} \triangle \mathrm{GEI}$ = residual GEI - original GEI.

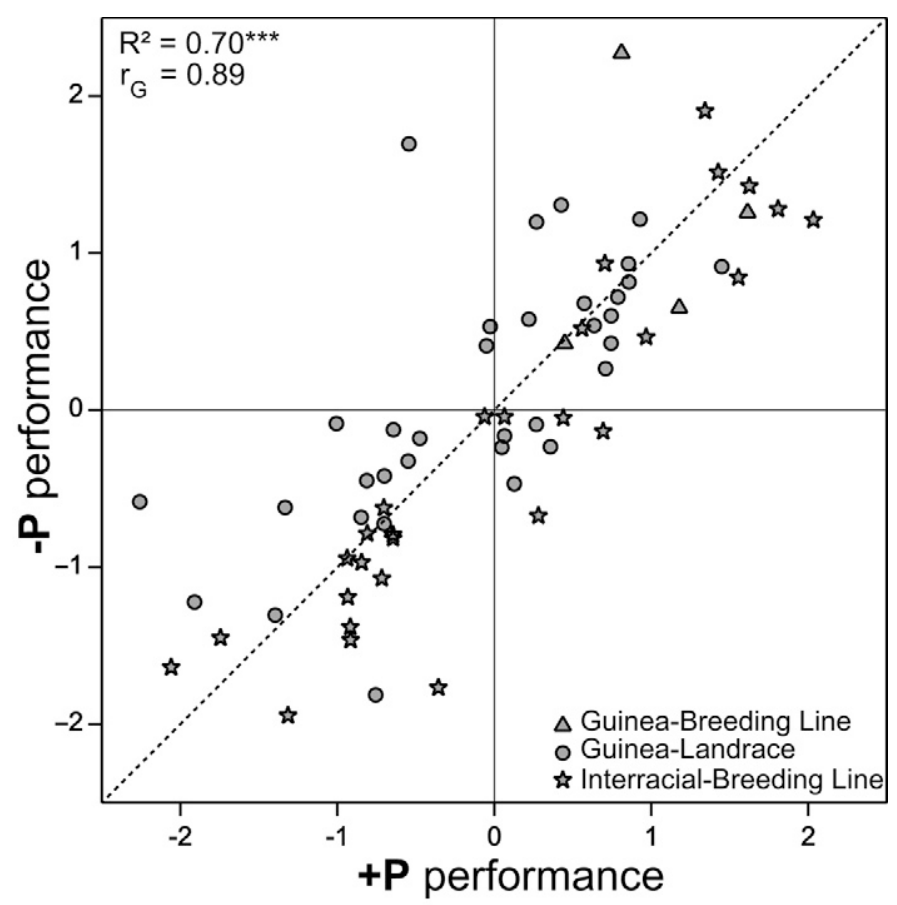

Figure 1. Grain yield performance as standardized best linear unbiased predictions $(\mu=0 ; \sigma=1)$ of 66 sorghum genotypes across eight trials without $(-P)$ and seven trials with $P$ fertilization $(+\mathrm{P})$, with the corresponding coefficient of determination $\left(R^{2}\right)$ and genetic correlation $\left(r_{\mathrm{G}}\right)$.

sum of all GEI components equaling the genotype variance component (Table 5) and contributed to the $h^{2}$ estimate across all $+\mathrm{P}$ environments not exceeding that of the $-\mathrm{P}$ environments. The $+\mathrm{P}$ trials showed relatively higher twoway interactions $(G \times Y, G \times L)$. Especially the genotype $\times$ location interaction $(G \times L)$ was much more important in the $+\mathrm{P}$ trials as seen in the variance component ratio of $\mathrm{G}: \mathrm{G} \times \mathrm{L}$ in $+\mathrm{P}(1: 0.43)$ vs. $-\mathrm{P}$ (1:0.13). Trial yield level and sowing date explained only very little of GEI in the $+\mathrm{P}$ trials, similar to the $-\mathrm{P}$ trials (Table 6). More GEI in the $+\mathrm{P}$ trials was explained by the annual total number of rain days (51\%) than by rain days during the growing season (27\%) (data not shown). A genotypic grouping factor based on photoperiod sensitivity could explain $27 \%$ of GEI in $+\mathrm{P}$, whereas it explained only $10 \%$ in $-\mathrm{P}$ conditions (data not shown).

\section{Relationship Between Performance Under Low- and High-Phosphorus Conditions}

The significant but rather small genotype $\times$ P-level interaction $(\mathrm{G} \times \mathrm{P})$ variance component estimate from the combined analysis over all 15 trials shows strong correspondence of genotypic performance between $+\mathrm{P}$ and $-\mathrm{P}$ conditions (data not shown). The genotype variance component explained most of the variation and had a ratio of 1:0.13 to $G$ $\times$ P. Most of the GEI was of a more complex three- or fourway interaction (data not shown), as also seen in the large variance component for genotype $\times$ environment $\times$ P-level interaction $(\mathrm{G} \times \mathrm{E} \times \mathrm{P})$ and the variance component ratio of $G: G \times E \times P(1: 0.7)$. The close relationship between genotypic grain yield performance in $-\mathrm{P}$ and $+\mathrm{P}$ conditions is also indicated by the large estimate of broad-sense heritability $\left(h^{2}\right.$ $=0.96)$ across P-levels and a rather high genetic correlation $\left(r_{\mathrm{G}}=0.89\right)$ between grain yield performance under $-\mathrm{P}$ and $+\mathrm{P}$ conditions. The generally strong agreement between genotypic performance in $+\mathrm{P}$ and $-\mathrm{P}$ conditions is seen by plotting grain yield BLUPs of $-\mathrm{P}$ vs. $+\mathrm{P}$, using standardized values with only a few genotypes showing major deviations from the 1:1 line that suggest some specific adaptation to $+\mathrm{P}$ or $-\mathrm{P}$ conditions (Fig. 1) and genotype $\times$ phosphorus crossover interactions (Fig. 2). Generally, the Guinea-landraces showed a better adaptation toward $-\mathrm{P}$, whereas the interracial breeding lines were more adapted to the $+\mathrm{P}$ conditions.

\section{Direct vs. Indirect Selection for Grain Yield Under -P and +P Conditions}

There was close correspondence between the top 10 (15\%) ranked genotypes for grain yield under $-\mathrm{P}$ and under $+\mathrm{P}$ conditions, with $60 \%$ of the genotypes being in common (Table 7). All 10 top-ranked genotypes under $-\mathrm{P}$ had grain yield BLUPs that were significantly $(P<0.01)$ larger than the overall $-\mathrm{P}$ mean (Table 7 ).

However, the relative effectiveness of indirect selection in $+\mathrm{P}$ for $-\mathrm{P}$ grain yield was predicted to be only $88 \%$ as effective as direct selection in $-\mathrm{P}\left(R_{\mathrm{id}} / R_{\mathrm{d}}=0.89 \star[0.95 / 0.96]=0.88\right)$. Additionally, the selection under $+\mathrm{P}$ conditions missed some of the highest ranked genotypes for $-\mathrm{P}$ grain yield (data not shown). Although selection under $+\mathrm{P}$ conditions retained 


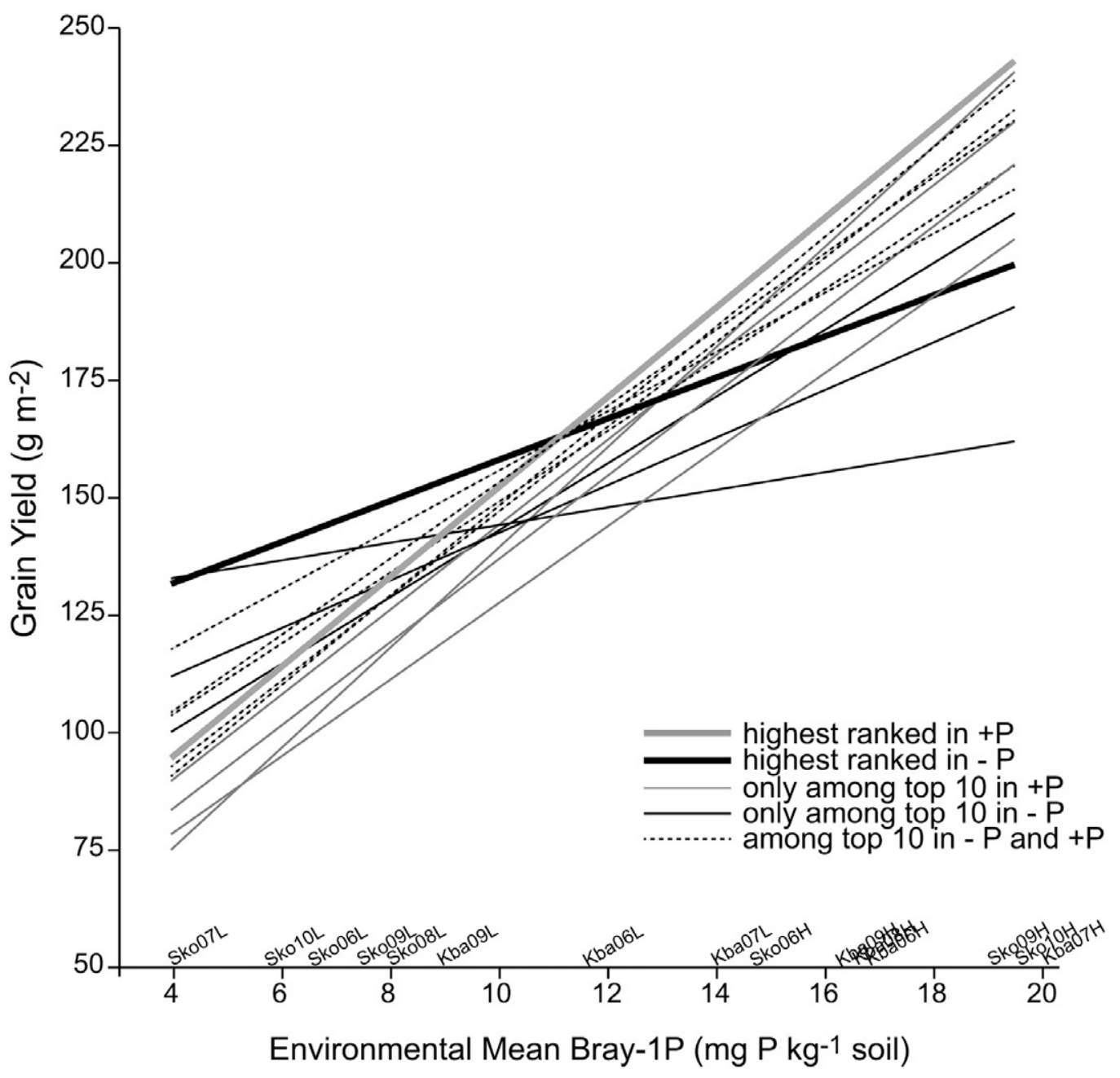

Figure 2. Linear regression of grain yield of 10 best-yielding sorghum genotypes in $-P$ (without $P$ fertilization) and $+P$ (with $P$ fertilization) conditions against the environmental mean Bray-1 P soil value. Slope estimates are significant $(t-$ prob. $\leq 0.05)$, except for genotypes NAFALENP6, IS 15401, and B2-5.

all five of the interracial breeding lines from the top $-\mathrm{P}$ set, it retained only one of the five Guinea-race breeding lines and landrace genotypes (data not shown). Further, higher selection intensity under $+\mathrm{P}$ accentuated the loss of the highest ranked genotypes for $-\mathrm{P}$ conditions. Thus, there is evidence of significant genotype $\times$ phosphorus crossover interaction among the top 10 yielding genotypes across the $-\mathrm{P}$ and the $+\mathrm{P}$ environments (Fig. 2). This was particularly the case for the top three genotypes $(\sim 5 \%)$ from $-\mathrm{P}$ and $+\mathrm{P}$ selections (Table 7 ). The genotypes NAFALENP6 and IS15401 showed especially superior yields relative to the other genotypes in very poor environments ( $<7 \mathrm{mg} \mathrm{P} \mathrm{kg}^{-1}$ soil), with an apparent crossover point between 9 and $11 \mathrm{mg} \mathrm{P} \mathrm{kg}^{-1}$ soil (Bray-1 P) (Fig. 2).

\section{DISCUSSION}

\section{Appropriateness of Test Environments for Assessing Efficiency of $-\mathrm{P}$ and $+\mathrm{P}$ Selection}

Our series of $-\mathrm{P}$ environments showed rather large yield and height reductions and heading delays relative to environments receiving $\mathrm{P}$ fertilization, suggesting that the $-\mathrm{P}$ and $+\mathrm{P}$ environments did differ for $\mathrm{P}$ stress. Yield reduction, heading delay, and reduced height in - $\mathrm{P}$ compared to $+\mathrm{P}$ have been reported for several crops (Rossiter, 1978; Fageria et al., 1988; Atlin and Frey, 1989; Wissuwa and Ae, 2001; Manske et al., 2001; Turk et al., 2003; Chen et al., 2008; Cichy et al., 2008; Parentoni et al., 2010), suggesting that our environmental selection based on yield differences, height reduction, and heading delay was appropriate. Furthermore, the yield levels in our $-\mathrm{P}$ trials were within the range common in Malian farmers' fields (FAO, 2010). Although the $-\mathrm{P}$ environments in Kolombada 2006 to 2008 received less total nitrogen $(\mathrm{N})$ than the corresponding $+\mathrm{P}$ fields, the $2008-\mathrm{P}$ trial was not included for the combined analysis due to lack of yield reduction, and the relative yield reductions of 2006 and 2007 were within the range of other pairs of trials with equivalent $\mathrm{N}$ in both $+\mathrm{P}$ and $-\mathrm{P}$. Also, genotype main effects and genotype $\times$ environment interaction (GGE) biplots (Yan and Kang, 2002) of $-\mathrm{P}$ environments did not reveal any distinct environment grouping relating to amounts of $\mathrm{N}$ fertilization (data not shown). The majority of our $-\mathrm{P}$ trials had Bray-1 P-levels 
Table 7. Ranks and best linear unbiased predictions for grain yield under $-P(G Y-P)$ and $+P(G Y+P)$ conditions of the 10 sorghum genotypes having the highest rank for grain yield across the eight $-\mathrm{P}$ trials and the corresponding selection differentials of the top $10(15 \%), 7(10 \%)$ and three $(5 \%)$ genotypes selected under $-\mathrm{P}$ conditions.

\begin{tabular}{|c|c|c|c|c|}
\hline Genotype & GY -P & Rank -P & $\mathrm{GY}+\mathrm{P}$ & Rank $+\mathrm{P}$ \\
\hline NAFALENP6 & $134.6^{\star \star \star}$ & 1 & $202.4^{\star \star \star}$ & 14 \\
\hline TIANDOUGOU & $127.1^{\star \star \star}$ & 2 & $218.4^{\star \star \star}$ & 8 \\
\hline IS 15401 & $122.8^{\star \star * *}$ & 3 & $161.8^{*}$ & 41 \\
\hline GRINKAN & $119.1^{\star \star \star}$ & 4 & $220.9^{* * *}$ & 7 \\
\hline 01-BE-F5P-15 & $117.3^{\star \star \star}$ & 5 & $226.9^{\star \star \star}$ & 3 \\
\hline B2-5 & $114.9^{\star \star \star}$ & 6 & $190.9 \mathrm{NS}^{\dagger}$ & 26 \\
\hline 04-KANIKO-F5DT-26 & $114.3^{\star \star \star}$ & 7 & $232.4^{\star \star \star}$ & 2 \\
\hline WELI & $113.9^{\star \star \star *}$ & 8 & $226.5^{\star \star \star}$ & 4 \\
\hline SAKOYKA-BA & $113.0^{\star \star \star}$ & 9 & $206.0^{\star \star}$ & 11 \\
\hline 00-SB-F5DT-5 & $112.9^{\star \star \star}$ & 10 & $239.1^{\star \star \star}$ & 1 \\
\hline Selection differential $15 \%$ & 30.7 & & 34.4 & \\
\hline Selection differential $10 \%$ & 33.1 & & 29.5 & \\
\hline Selection differential $5 \%$ & 39.8 & & 16.1 & \\
\hline Grand mean & 88.3 & & 178.1 & \\
\hline
\end{tabular}

* Significantly different from grand mean in same column at $p<0.05$ in Waldstatistics in comparison contrasts.

** Significantly different from grand mean in same column at $p<0.01$ in Waldstatistics in comparison contrasts.

*** Significantly different from grand mean in same column at $p<0.001$ in Waldstatistics in comparison contrasts.

† NS = nonsignificant.

below $10 \mathrm{ppm} \mathrm{P}\left(10 \mathrm{mg} \mathrm{P} \mathrm{kg}^{-1}\right.$ soil), thus within the range where P stress for WA sorghums is expected (Doumbia et al., 1993) and the range commonly observed in farmers' sorghum fields in Mali $(N=207$, range $=1.6-36.2$, mean $=7.4$, median $=5.5$; unpublished data, 2012). Thus, our -P environments appear to be relevant to Malian low-input sorghum production conditions.

Contrary to studies in maize by Parentoni et al. (2010), we did not detect a clear relationship between RYR and the genetic correlation $\left(r_{\mathrm{G}}\right)$ between yield in $-\mathrm{P}$ vs. $+\mathrm{P}$ conditions. This result may indicate that WA sorghums show generally fairly good adaptation to low-P conditions, even though general high yield differences between $-\mathrm{P}\left(88.3 \mathrm{gm}^{-2}\right)$ and $+\mathrm{P}\left(178.1 \mathrm{gm}^{-2}\right)$ existed. In fact, WA farmers consider sorghum as a crop for poor soils, and its capacity to produce yield without fertilization is one major factor contributing to its extensive cultivation and its importance as a staple cereal.

\section{Selection in -P Conditions is Feasible}

Heritabilities and/or repeatabilities for grain yield under lowinput conditions are generally observed and expected to be lower due to higher error levels relative to high-input conditions (Ceccarelli, 1989, 1996; Atlin and Frey, 1990). Studies with contrasting $\mathrm{P}$ fertility levels showed significantly lower $h^{2}$ in the $-\mathrm{P}$ environments (Atlin and Frey, 1989; Ding et al., 2012). We also observed higher error levels (aVD) within and across the $-\mathrm{P}$ trials compared to $+\mathrm{P}$ trials. However, the greater genetic variation (GCV) under $-\mathrm{P}$ conditions, especially those below the crossover point (at $11 \mathrm{ppm} \mathrm{P} \mathrm{[11} \mathrm{mg}$ $\mathrm{P} \mathrm{kg}^{-1}$ soil]), contributed to similarly high $h^{2}$ estimates across both $-\mathrm{P}$ and $+\mathrm{P}$ trials. Greater genetic variation and better genotypic discrimination for grain yield in environments below crossover points was also observed in simulations and GEI studies by Simmonds (1991) and Ceccarelli (1996), respectively. The observed high $h^{2}$ estimates across our $-\mathrm{P}$ and $+\mathrm{P}$ trials were partly due to the rather large number of trials with little GEI and to the exclusion of some trials which showed environmental constraints.

Also, GEI in $-\mathrm{P}$ was rather small compared to the genotypic variance component, with little indication of high two-way interactions $(G \times L, G \times Y)$ that otherwise needed to be considered for achieving more effective $-\mathrm{P}$ selection. Although rainfall was an important factor explaining GEI, it actually explained more GEI in $+\mathrm{P}$. Most of the GEI in $-\mathrm{P}$ was of a complex $G \times Y \times L$ structure and was therefore not exploitable by further subdivision in mega-environments, as pointed out by Atlin et al. (2000, 2001). Therefore, the limited GEI observed across our $-\mathrm{P}$ environments despite ample sampling of years, sowing dates, and productivity levels suggests that BLUPs across $-\mathrm{P}$ trials may be used for selecting genotypes with superior $-\mathrm{P}$ adaptation and yield stability. However, a grouping of environments by rainfall zones may be helpful and testing in different rainfall zones should be considered for yield stability estimation.

The relatively lower GEI in $-\mathrm{P}$ vs. $+\mathrm{P}$, especially for location, may be due in part to consequences of differential flowering responses of photoperiod-sensitive and less sensitive materials. Genetic variance for date of heading was higher in $+\mathrm{P}$ compared to $-\mathrm{P}$ environments. Although all varieties showed delayed flowering in $-\mathrm{P}$, the less photoperiod-sensitive materials tended to have greater delays (data not shown), and thus reduced flowering time differences between these normally early-flowering materials and the typically later-flowering photoperiodsensitive varieties under the $-\mathrm{P}$ conditions.

Therefore, genotypic selection for grain yield in researcher managed $-\mathrm{P}$ environments appears to be feasible and relevant to farmer's low-P conditions for sorghum in Sudanian WA, especially in test environments with Bray-1 $\mathrm{P}$ values below 9 and $11 \mathrm{ppm}$ (9 and $11 \mathrm{mg} \mathrm{P} \mathrm{kg}^{-1}$ soil). The application of spatial adjustment methods (as in this study) can increase the repeatability in single trials (Leiser et al., 2012) and the broad-sense heritability across environments (data not shown) and, thus, further enhance the precision and efficiency of genotypic selection in low-input conditions.

\section{Direct Selection in -P Conditions is More Efficient and There is a Need for Specific Adaptation to -P Conditions}

The correspondence of sorghum varieties' yield performances under $-\mathrm{P}$ and $+\mathrm{P}$ conditions was surprisingly high relative to 
observations in other crops like oat (Avena sativa L.), common bean (Phaseolus vulgaris L.), rape (Brassica napus L.) seeds, and maize (Zea mays L.) (Atlin and Frey, 1989; Beebe et al., 1997; Hammond et al., 2009; Parentoni et al., 2010; Ding et al., 2012). The high genetic correlation over P-levels and the small $\mathrm{G} \times \mathrm{P}$ variance component suggest that selection for general grain yield performance could be done either under $-\mathrm{P}$ or $+\mathrm{P}$ conditions. Also, these results suggest that the Guinea-race sorghum germplasm tested in this study has fairly good adaptation to low-P conditions. This may reflect the history of WA farmer's cultivation and selection of this race of sorghum over millennia under low-input conditions. Even today Malian farmers in intensifying production zones with $>900 \mathrm{~mm}$ annual rainfall still extensively cultivate sorghum in the less fertile fields, knowing that sorghum can more dependably produce grain than can maize under such conditions. The rather weak relationship between RYR and $\mathrm{r}_{\mathrm{G}}$ in this study compared to maize (Parentoni et al., 2010) also points to a general good adaptation of WA Guinea-race germplasm to low-P conditions.

However, specific adaptation to $-\mathrm{P}$ conditions was shown by certain varieties in our study, such as IS 15401, and higher expected gains for grain yield in $-\mathrm{P}$ conditions were predicted via direct selection under $-\mathrm{P}$ conditions. Therefore, the careful identification of breeding objectives and target environments for which improvements are sought will be important for deciding on which testing environments to emphasize.

In this paper we have compared indirect selection under $+\mathrm{P}$ conditions to direct selection under $-\mathrm{P}$ conditions. These two strategies imply that in a future breeding program only one of the two types of trial will be used. If for some reason both types of trial will be conducted, the most efficient strategy may be to combine data from both types of trials. This is implemented most conveniently by fitting Model [5] and computing BLUPs of GP for the $-\mathrm{P}$ condition. These BLUPs will combine the information across $\mathrm{P}$-conditions in an optimal way, exploiting the genetic correlation between $+\mathrm{P}$ and $-\mathrm{P}$ conditions (Piepho and Möhring, 2005; Przystalski et al., 2008). We predicted grain yield BLUPs with both approaches and found a very strong agreement between $-\mathrm{P}(r=0.9942)$ as well as $+\mathrm{P}$ $(r=0.9895)$ BLUPs derived from a model, not exploiting genetic correlations (as used in Table 7), and Model [5], respectively. In the $-\mathrm{P}$ conditions all top 10 genotypes (as in Table 7) remained the same with slight rank changes, whereas in $+\mathrm{P}$ only nine out of 10 genotypes remained within the 10 top ranked genotypes (data not shown).

Low $\mathrm{P}$ availability in WA soils is very prevalent $(<7$ ppm Bray-1 P [7 mg P kg-1 soil]) (unpublished data, 2012), especially in sorghum and pearl millet fields (Buerkert et al., 2001). Furthermore, inadequate infrastructure, high prices, lack of credit, and risk aversion limit many African farmers' use of fertilizers, resulting in average annual fertilizer application rates of 5 to $8 \mathrm{~kg} \mathrm{NPK} \mathrm{ha}^{-1}$ (Jayne et al., 2003; Morris 2007; Bekunda et al., 2011). The fact that our $-\mathrm{P}$ environments appeared to better reflect farmers' conditions than the $+\mathrm{P}$ environments encourages more extensive sorghum varietal testing under $-\mathrm{P}$ conditions for WA. Further, assessments of flowering delay and plant height under low-P variety testing could help avoid risks of poor grain fill with early cessation of seasonal rains and transhumant livestock damage of shorter height plants under low-P field conditions in WA. The long-term perspective of depleting worldwide $\mathrm{P}$ resources (50-370 yr) and rising fertilizer prices (Cordell et al., 2009; Van Kauwenbergh, 2010; Bekunda et al., 2011; Cooper et al., 2011; Jasinski, 2012), combined with continued population growth, point to the importance of crop breeding for $-\mathrm{P}$ conditions on a worldwide scale (Gregory and George, 2011).

\section{Acknowledgment}

This paper is dedicated to our recently deceased colleague and friend Heiko K. Parzies. The staff of the Sorghum Breeding Program at the Institut de Economie Rural and the International Crops Research Institute for the Semi-Arid Tropics in Mali who conducted the trials in this study, the financial support of the McKnight Foundation and the Generation Challenge Program, and the statistical support we received from the University of Reading are gratefully acknowledged. Further, we would also like to thank the Institut de l'Environnement et des Recherches Agricoles in Burkina Faso for providing some of the genotypes.

\section{References}

Atlin, G.N., R.J. Baker, K.B. McRae, and X. Lu. 2000. Selection response in subdivided target regions. Crop Sci. 40:7-13. doi:10.2135/cropsci2000.4017

Atlin, G.N., M. Cooper, and A. Bjornstad. 2001. A comparison of formal and participatory breeding approaches using selection theory. Euphytica 122:463-475. doi:10.1023/A:1017557307800

Atlin, G.N., and K.J. Frey. 1989. Predicting the relative effectiveness of direct versus indirect selection for oat yield in three types of stress environments. Euphytica 44:137-142. doi:10.1007/BF00022608

Atlin, G.N., and K.J. Frey. 1990. Selecting oat lines for yield in low-productivity environments. Crop Sci. 30:556-561. doi:10.2135/cropsci1990.0011183X003000030017x

Beebe, S., J. Lynch, N. Galwey, J. Tohme, and I. Ochoa. 1997. A geographical approach to identify phosphorus-efficient genotypes among landraces and wild ancestors of common bean. Euphytica 95:325-338. doi:10.1023/A:1003008617829

Bekunda, M., D. Cordell, J. Corman, J. Johnston, A. Rosemarin, I. Salcedo, K. Syers, and T. Lougheed. 2011. Phosphorus and food production. In: UNEP yearbook: Emerging issues in our global environment. UNEP, Nairobi. p. 34-45.

Bray, R., and L.T. Kurtz. 1945. Determination of total, organic, and available forms of phosphorus in soils. Soil Sci. 59:39-46. doi:10.1097/00010694-194501000-00006

Buerkert, A., A. Bationo, and H.-P. Piepho. 2001. Efficient phosphorus application strategies for increased crop production in sub-Saharan West Africa. Field Crops Res. 72:1-15. doi:10.1016/S0378-4290(01)00166-6 
Ceccarelli, S. 1989. Wide adaptation: How wide? Euphytica 40:197-205.

Ceccarelli, S. 1996. Adaptation to low/high input cultivation. Euphytica 92:203-214. doi:10.1007/BF00022846

Chen, J., L. Xu, Y. Cai, and J. Xu. 2008. QTL mapping of phosphorus efficiency and relative biologic characteristics in maize (Zea mays L.) at two sites. Plant Soil 313:251-266. doi:10.1007/s11104-008-9698-x

Cichy, K.A., S.S. Snapp, and M.W. Blair. 2008. Plant growth habit, root architecture traits and tolerance to low soil phosphorus in an Andean bean population. Euphytica 165:257-268. doi:10.1007/s10681-008-9778-2

Cooper, J., R. Lombardi, D. Boardman, and C. Carliell-Marquet. 2011. The future distribution and production of global phosphate rock reserves. Resour. Conserv. Recycling 57:7886. doi:10.1016/j.resconrec.2011.09.009

Cooper, M., and I.H. DeLacy. 1994. Relationships among analytical methods used to study genotypic variation and genotype-by-environment interaction in plant breeding multi-environment experiments. Theor. Appl. Genet. 88:561-572. doi:10.1007/BF01240919

Cordell, D., J.-O. Drangert, and S. White. 2009. The story of phosphorus: Global food security and food for thought. Global Environ. Change 19:292-305. doi:10.1016/j. gloenvcha.2008.10.009

Cullis, B.R., A.B. Smith, and N.E. Coombes. 2006. On the design of early generation variety trials with correlated data. J. Agric. Biol. Environ. Stat. 11:381-393. doi:10.1198/108571106X154443

De Wet, J.M.J., and J.R. Harlan. 1972. The origin and domestication of Sorghum bicolor. Econ. Bot. 25:128-135. doi:10.1007/BF02860074

Ding, G., Z. Zhao, Y. Liao, Y. Hu, L. Shi, Y. Long, and F. Xu. 2012. Quantitative trait loci for seed yield and yield-related traits, and their responses to reduced phosphorus supply in Brassica napus. Ann. Bot. 109: 747-759.

Doumbia, M.D., L.R. Hossner, and A.B. Onken. 1993. Variable sorghum growth in acid soils of subhumid West Africa. Arid Soil Res. Rehabil. 7:335-346. doi:10.1080/15324989309381366

Doumbia, M.D., L.R. Hossner, and A.B. Onken. 1998. Sorghum growth in acid soils of West Africa: Variations in soil chemical properties. Arid Land Res. Manage. 12:179-190. doi:10.1080/15324989809381507

Doumbia, M.D., A. Sidibé, A. Bagayoko, M.A. Diarra, A. Bationo, R.A. Kablan, R.S. Yost, L.R. Hossner, and F.M. Hons. 2003. Recommandations spécifiques d'engrais: Calibration et validation du module phosphore du modèle NuMaSS. Afr. Crop Sci. J. 11:17-26. doi:10.4314/acsj.v11i1.27564

Fageria, N.K., R.J. Wright, and V.C. Baligar. 1988. Rice cultivar evaluation for phosphorus use efficiency. Plant Soil 111:105109. doi:10.1007/BF02182043

FAO. 2010. FAO Stat: Sorghum. http://faostat.fao.org/site/567/ default.aspx (accessed 5 Feb. 2012).

Gregory, P.J., and T.S. George. 2011. Feeding nine billion: The challenge to sustainable crop production. J. Exp. Bot. 62:5233-5239. doi:10.1093/jxb/err232

Hammond, J.P., M.R. Broadley, P.J. White, G.J. King, H.C. Bowen, R. Hayden, M.C. Meacham, A. Mead, T. Overs, W.P. Spracklen, and D.J. Greenwood. 2009. Shoot yield drives phosphorus use efficiency in Brassica oleracea and correlates with root architecture traits. J. Exp. Bot. 60:1953-1968. doi:10.1093/jxb/erp083
Holford, I.C.R. 1997. Soil phosphorus: Its measurement, and its uptake by plants. Aust. J. Soil Res. 35:227-240. doi:10.1071/ S96047

IFDC. 2006. Global leaders launch effort to turn around Africa's failing agriculture: New study reports three-quarters of African farmlands plagued by severe degradation. http:// www.rockefellerfoundation.org/news/press-releases/globalleaders-launch-effort-turn (accessed 4 June 2012).

Jasinski, S.M. 2012. Phosphat rock. http://minerals.usgs.gov/ minerals/pubs/commodity/phosphate_rock/mcs-2012phosp.pdf (accessed 9 Feb. 2012).

Jayne, T.S., V. Kelly, and E. Crawford. 2003. Fertilizer consumption trends in Sub-Saharan Africa. http://www.aec.msu.edu/fs2/ polsyn/number69.pdf (accessed 6 Feb. 2012).

Leiser, W.L., H.F.W. Rattunde, H.-P. Piepho, and H.K. Parzies. 2012. Getting the most out of sorghum low-input field trials in West Africa using spatial adjustment. J. Agron. Crop Sci. 198:349-359. doi:10.1111/j.1439-037X.2012.00529.x

Manske, G.G.B., J.I. Ortiz-Monasterio, M. van Ginkel, R.M. González, R.A. Fischer, S. Rajaram, and P.L.G. Vlek. 2001. Importance of $\mathrm{P}$ uptake efficiency versus $\mathrm{P}$ utilization for wheat yield in acid and calcareous soils in Mexico. Eur. J. Agron. 14:261-274. doi:10.1016/S1161-0301(00)00099-X

Manu, A., A. Bationo, and S.C. Geiger. 1991. Fertility status of selected millet producing soils of West Africa with emphasis on phosphorus. Soil Sci. 152:315-320. doi:10.1097/00010694199111000-00001

Möhring, J., and H.-P. Piepho. 2009. Comparison of weighting in two-stage analysis of plant breeding trials. Crop Sci. 49:19771988. doi:10.2135/cropsci2009.02.0083

Morris, M.L. 2007. Fertilizer use in African agriculture: Lessons learned and good practice guidelines. World Bank Publications. www-wds.worldbank.org/external/default/ WDSContentServer/WDSP/IB/2007/03/15/000310607_20 070315153201/Rendered/PDF/390370AFR0Fert101OFFICI AL0USE0ONLY1.pdf (accessed 27 June 2012).

Parentoni, S., C. de Souza, Jr., V. de Carvalho Alves, E. Gama, A. Coelho, A. de Oliveira, P. Guimarães, C. Guimarães, M. Vasconcelos, C.A.P. Pacheco, W.F. Meirelles, J.V. de Magalhães, L.J. Moreira Guimarães, A.R. da Silva, F. Ferreira Mendes, and R.E. Schaffert. 2010. Inheritance and breeding strategies for phosphorus efficiency in tropical maize (Zea mays L.). Maydica 55:1-15.

Piepho, H.-P. 1999. Stability analysis using the SAS system. Agron. J. 91:154-160. doi:10.2134/agronj1999.00021962009 $100010024 \mathrm{x}$

Piepho, H.-P., and J. Möhring. 2005. Best linear unbiased prediction of cultivar effects for subdivided target regions. Crop Sci. 45:1151-1159. doi:10.2135/cropsci2004.0398

Piepho, H.-P., and J. Möhring. 2007. Computing heritability and selection response from unbalanced plant breeding trials. Genetics 177:1881-1888. doi:10.1534/genetics.107.074229

Piepho, H.P., J. Möhring, A.E. Melchinger, and A. Büchse. 2008. BLUP for phenotypic selection in plant breeding and variety testing. Euphytica 161:209-228. doi:10.1007/s10681-0079449-8

Przystalski, M., A. Osman, E.M. Thiemt, B. Rolland, L. Ericson, H. Østergård, L. Levy, M. Wolfe, A. Büchse, H.-P. Piepho, and P. Krajewski. 2008. Comparing the performance of cereal varieties in organic and non-organic cropping systems in different European countries. Euphytica 163:417-433. doi:10.1007/s10681-008-9715-4 
Rattunde, H.F.W., E. Weltzien, P.J. Bramel-Cox, K. Kofoid, C.T. Hash, W. Schipprack, J.W. Stenhouse, and T. Presterl. 1997. Population improvement of pearl millet and sorghum: Current research, impact and issues for implementation. In: Proceedings of the International Conference on Genetic Improvement of Sorghum and Pearl Millet, Lubbock, TX. 22-27 Sept. 1997. p. 188-212.

Rossiter, R.C. 1978. Phosphorus deficiency and flowering in subterranean clover (T. subterraneum L.). Ann. Bot. (Lond.) 42:325-329.

Simmonds, N. 1991. Selection for local adaptation in a plant breeding programme. Theor. Appl. Genet. 82:363-367. doi:10.1007/BF02190624

Smith, A., B. Cullis, and A. Gilmour. 2001. The analysis of crop variety evaluation data in Australia. Aust. N. Z. J. Stat. 43:129-145. doi:10.1111/1467-842X.00163

Turk, M.A., A.M. Tawaha, and M.K.J. El Shatnawi. 2003. Response of lentil (Lens culinaris Medik) to plant density, sowing date, phosphorus fertilization and ethephon application in the absence of moisture stress. J. Agron. Crop Sci. 189:1-6. doi:10.1046/j.1439-037X.2003.00002.x

Van Kauwenbergh, S. 2010. World phosphate rock reserves and resources. Center for Strategic and International Studies, IFDC. Www.ifdc.org/Media_Info/Press_Releases/ September_2010/IFDC_Report_Indicates_Adequate_ Phosphorus_Resource (accessed 5 Feb. 2012).

Vom Brocke, K., G. Trouche, E. Weltzien, C.P. BarroKondombo, E. Gozé, and J. Chantereau. 2010. Participatory variety development for sorghum in Burkina Faso: Farmers' selection and farmers' criteria. Field Crops Res. 119:183-194. doi:10.1016/j.fcr.2010.07.005

Wissuwa, M., and N. Ae. 2001. Genotypic variation for tolerance to phosphorus deficiency in rice and the potential for its exploitation in rice improvement. Plant Breed. 120:43-48. doi:10.1046/j.1439-0523.2001.00561.x

Yan, W., and M.S. Kang. 2002. GGE biplot analysis: A graphical tool for breeders, geneticists, and agronomists. 1st ed. CRC Press, Boca Raton, FL. 